\title{
AN ANALYTICAL AND EXPERIMENTAL STUDY OF ULTRASONIC LINEAR MOTORS
}

\author{
Ramiro Velázquez, Hermes Hernández, Carlos A. Gutiérrez, Pedro Rodrigo
}

Preliminary notes

Ultrasonic linear motors (ULMs) are widely used in many industrial applications and a full characterization of their behaviour is often needed. This paper presents a detailed analytical-experimental study of ULMs. First, the general structure and operation principle of ULMs are introduced. The actuator mechanics is then described using a simple piezoelectric model. Since, in practice, ULMs are most often used as actuators for positioning mechanisms, the proposed model includes electromechanical relations which offer designers a broad range of possibilities for precise positioning and reliable model-based control. Finally, ULMs are experimentally investigated to determine the conditions that allow an optimal performance.

Keywords: linear actuator; modelling; numerical simulation; piezoelectric motor; principle of inertia; transducer; ultrasonic linear motor (ULM)

Analitička i eksperimentalna analiza ultrazvučnih linearnih motora

Prethodno priopćenje

Ultrazvučni linearni motori (ULM-i) uvelike se koriste u mnogim industrijskim primjenama te je često potrebno u potpunosti odrediti njihovo ponašanje. Ovaj rad pruža detaljnu analitičko-eksperimentalnu analizu ULM-a. Najprije se daju opća struktura i princip rada ULM-a. Mehanika pokretača (aktuatora) se zatim opisuje pomoću jednostavnog piezoelektričnog modela. Budući da se u praksi ULM-i najčešće upotrebljavaju kao pokretači mehanizama pozicioniranja, predloženi model uključuje elektromehaničke odnose koji projektantima nude širok raspon mogućnosti za precizno pozicioniranje i pouzdanu kontrolu pomoću modela. Konačno, pokusima su određeni uvjeti koji omogućuju optimalnu performansu.

Ključne riječi: linearni pokretač (aktuator); modeliranje; numerička simulacija; piezoelektrični motor; princip inercije; ultrazvučni linearni motor (ULM)

\section{Introduction}

Electromagnetic motors were invented more than a hundred years ago and yet, they still dominate the industry: DC motors, servomotors, and stepping motors are traditionally used to achieve rotational motion and, through ball-screw mechanisms, linear motion. Even though the popularity and advantages of electromagnetic actuators are indisputable, it is well-known that they present serious drawbacks at the micro/mesoscale: upon dimension reduction 1) system complexity increases significantly and 2) energy efficiency decreases considerably. Without a drastic improvement in magnetic or superconducting materials, electromagnetic technology seems limited to solve these problems.

Applications for micro/miniature actuators abound in diverse fields such as medicine, bio-engineering, electronics, robotics, aeronautics, and the automotive industry. Solutions have been just as diverse with designs using traditional actuation technologies such as electromagnetic, pneumatics, and hydraulics, as well as smart materials such as piezoelectric ceramics, shape memory alloys (SMAs), polymer gels, and electrorheological (ER) fluids.

In fact, the interest on smart materials has grown in the last decades due to their unique properties. This class of materials has the ability of changing its shape, size, stiffness, among other properties, through the imposition of electrical, electromagnetic, temperature, or stress fields.A comprehensive survey on smart materials and their properties can be found in [1].

A new class of motors using high power ultrasonic energy is gaining widespread attention. In particular, ultrasonic motors made with piezoelectric ceramics have become interesting actuators in the micro/meso scale.

An ultrasonic motor is a type of electric motor powered by the ultrasonic vibration of a piezoelectric component, the shaft, placed against another component, the slider. This concept dates to the 1970s when IBM successfully implemented the first working prototype [2] and the former USSR presented some mechanisms based on the same principle $[3,4]$. Due to the difficulty in maintaining constant vibration amplitude with temperature rise, wear, and tear, ultrasonic motors were not of much practical use at that time. During the $80 \mathrm{~s}$, the semiconductor industry began to request much more precise, sophisticated, and free from magnetic field noise actuators. This accelerated the development of ultrasonic motors. Sashida and Kenjo significantly improved the previous designs and were the first to use the system's resonance to create vibrations. They earned the ultrasonic motor name by operating at frequencies in the ultrasonic range $(>20 \mathrm{kHz})[5]$.

Some advantages of ultrasonic motors include: compact size, simple structure, high torque densities at low speed, fast response, self-locking, long-travel intermittence motion, excellent controllability of starting/stopping/reversing, and efficiency insensitive to size. Two main drawbacks are the necessity for a high frequency power supply and less durability due to frictional drive [6].

Ultrasonic linear motors (ULMs) are devices commonly used for zooming or auto-focusing functions in imaging systems of personal computers, mobile phones, digital cameras, video equipment, PDAs, etc. Recently, their real potential is just beginning to be exploited in applications as diverse as refreshable tactile displays [7], medical instruments [8], MEMS [9], toys [10], precision watches [11], industrial robots [12], micro-robotics [13, 14], among others. Due to their compact size, ULMs will be undoubtedly in large demand over the next decade mostly in the consumer electronics market.

To fully exploit the performance of these actuators, an analytical-experimental framework for evaluating their 
mechanics is essential. This paper presents a comprehensive review of the main characteristics of ULMs and intends to serve as a practical guide for simple/fast/reliable numerical analysis and experimental evaluation of their behaviour.

The rest of the paper is organized as follows: the general structure and operation principle of ULMs are first introduced. Then, a simple yet original electromechanical model to simulate its behaviour is proposed. A series of experimental results performed on a commercially available ULM are presented to illustrate their actuating properties. Finally, the paper concludes summarizing the main concepts and results.

\section{Structure and operating principle}

ULMs simply consist of a shaft, a mobile element or slider, and a piezoelectric ceramic disk (Fig. 1a). They can be found from several manufacturers in the $3 \div 15$ $\mathrm{mm}$ range which satisfies most of the portable consumer electronic motor demands. Fig. 1b shows for example, one of the smallest ULMs commercially available [15]. This device is miniature and ultra-lightweight: $2,4 \mathrm{~mm}$ diameter, 11,6 mm length, and $370 \mathrm{mg}$ mass. It will be used as the sample in this study for both numerical simulation and experimental evaluation.

The ceramic disk consists of a rigid part and a transducer. When voltage is applied, the transducer vibrates creating upward/downward fluctuations which are transferred to both shaft and slider (Fig. 2).

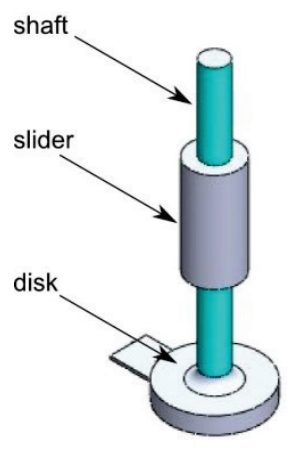

a)

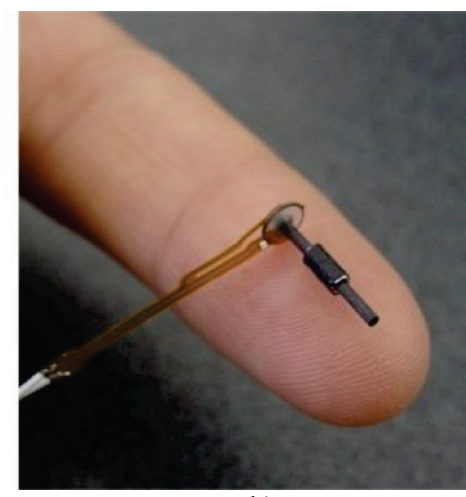

b)
Figure 1 ULMs: a) conceptual design and b) miniature Prototype from PiezoTech [15]

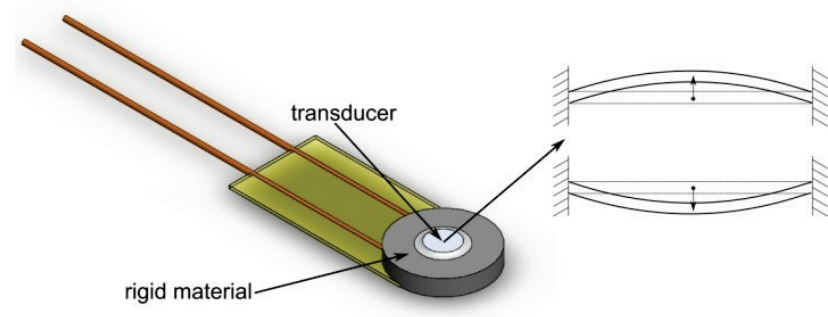

Figure 2 Structure of the piezoelectric ceramic disk and vibration of the transducer

Its linear motion is based on the principle of inertia displacement by high-frequency square wave electrical potential [16]. This operation principle is shown in Fig. 3a: (1) at the initial position, the motor is not energized, the shaft is in position $\mathrm{A}$ and the slider is located in position $x_{0}$. (2) When maximum voltage is applied, both shaft and slider move together a distance A (i.e. shaft to position $2 A$ and slider to position $x_{0}+A$ ). (3) As voltage falls to zero, the shaft slips backwards a distance $2 A$. However, the slider remains in its position because of its inertia. (4) When voltage increases to its maximum, both shaft and slider move again together a distance $2 A$ (i.e. shaft to position $2 \mathrm{~A}$ and slider to position $x_{0}+3 A$ ). The cycle repeats: (5) voltage decreases, shaft goes back to 0 while the slider remains in $x_{0}+3 A$. (6) Voltage increases, the shaft goes to position $2 A$, and the slider moves to position $x_{0}+5 A$.

Fig. $3 \mathrm{~b}$ shows the corresponding square wave driving electrical signal.

Fig. 3 shows the slider moving from left to right. Reverse motion can be achieved by inverting the duty cycle of the square wave electrical potential.
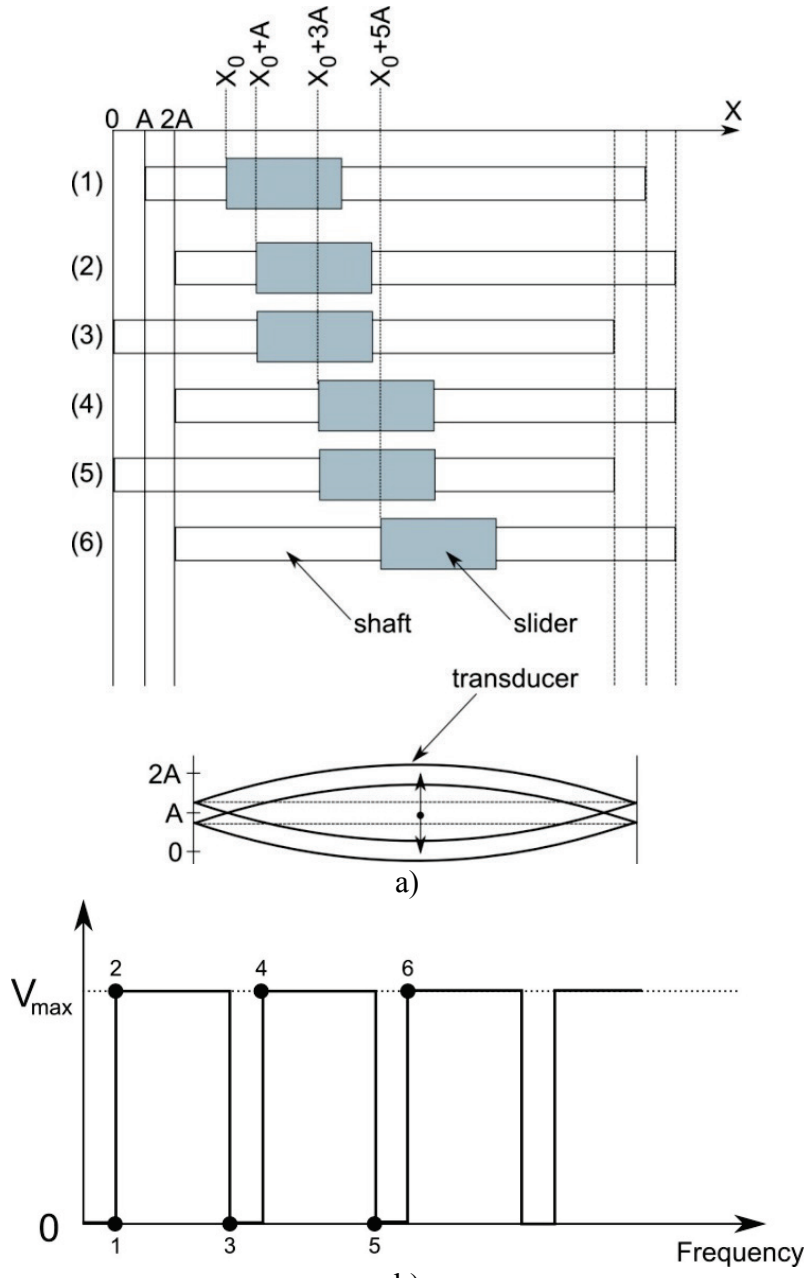

b)

Figure 3 a) The principle of inertia displacement and b) the square wave driving electrical signal.

\section{Modelling ULMs}

ULMs' modelling is based on piezoelectric ceramics which are a special type of dielectric materials known for the piezoelectric and reverse piezoelectric effects. The piezoelectric effect causes a dielectric to produce an electrical potential when it is subjected to mechanical stress. In contrast, the reverse piezoelectric effect causes the dielectric to become strained when it is placed in an electric field. 
Fig. 4 shows a schematic representation of both effects. Naturally, our interest focuses on the reverse piezoelectric effect. In this one, a voltage is produced in the dielectric when it is placed in an electric field. Due to the piezo-effect, the voltage generates a transduced force which, through a mechanical relation, results in an elongation.

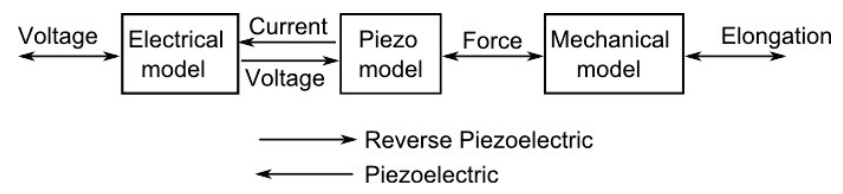

Figure 4 Block diagram of the piezoelectric and reverse piezoelectric effects

A well-known description of the piezoelectric effect was published in 1987 by a standards committee of the IEEE [17]. Since then, extensive work has been devoted to model the piezoelectric effect. Some representative works are $[18 \div 23]$.

A fairly accurate overall electromechanical model of both effects has been proposed by Goldfarb and Celanovic in [24]. Fig. 5a shows their simplified model for the reverse piezoelectric effect.

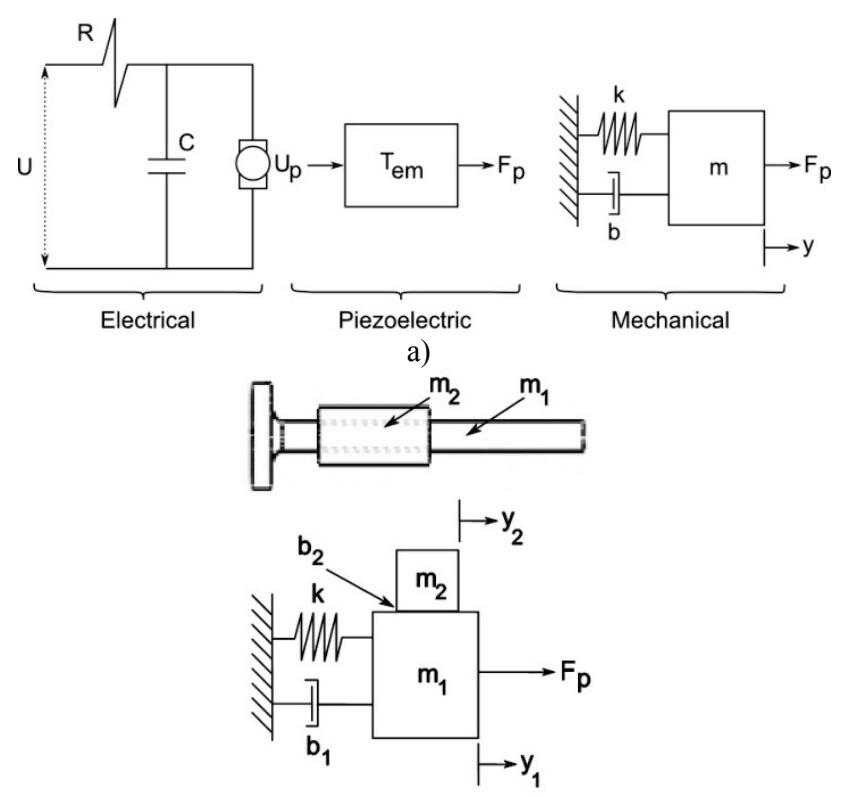

b)

Figure 5 a) Simplified electromechanical model for the reverse piezoelectric effect and b) mechanical model adapted for ULMs

Here, the electrical model is basically represented by an RC circuit. The piezo effect is represented by $T_{\mathrm{em}}$, which is an electromechanical transducer with transformer ratio $T_{\mathrm{em}}$. The voltage $U_{\mathrm{p}}$ is due to the piezo effect. The force $F_{\mathrm{p}}$ is the transduced force from the electrical side and mechanically drives the piezo material. The resulting elongation of the piezoelectric actuator is denoted by $y$. The mechanical relation between $F_{\mathrm{p}}$ and $y$ is denoted by a simple mass-spring-damper system.

For ULMs, the mechanical relation can be adapted as shown in Fig. 5b. Here, the mass $m_{1}$ moved by the transducer is the shaft while mass $m_{2}$ is the mass of the slider. The damping ratio $b_{1}$ is due to the transducer, $b_{2}$ is the viscous friction between the shaft and slider, and $k$ is the equivalent stiffness.
The complete set of electromechanical transfer functions for ULMs is as follows:

$$
\begin{aligned}
& \frac{U_{\mathrm{p}}(s)}{U(s)}=\frac{1}{R C s+1}, \\
& F_{\mathrm{p}}(s)=T_{\mathrm{em}} U_{\mathrm{p}}(s), \\
& \frac{Y_{2}(s)}{F_{\mathrm{p}}(s)}=\frac{b_{2} s}{\left(m_{2} s^{2}+b_{2} s\right)\left[m_{1} s^{2}+\left(b_{1}+b_{2}\right) s+k\right]-b_{2}{ }^{2} s^{2}} .
\end{aligned}
$$

The value of the parameters involved in these equations can be obtained from the manufacturer [15] or they can be experimentally or numerically estimated [7]. For example, for the ULM prototype shown in Fig. 1b values obtained are given in Tab. 1.

Table 1 Summary of the parameters involved in the ULM sample

\begin{tabular}{|l|c|c|}
\hline \multicolumn{1}{|c|}{ Parameter } & Value & Unit \\
\hline Resistance $R$ & 340 & $\Omega$ \\
\hline Capacitance $C$ & $1,7 \times 10^{-9}$ & $\mathrm{~F}$ \\
\hline Transducer ratio $T_{\mathrm{em}}$ & 0,0075 & $\mathrm{~N} / \mathrm{V}$ \\
\hline Mass $m_{1}$ & $10 \times 10^{-6}$ & $\mathrm{~kg}$ \\
\hline Mass $m_{2}$ & $0,52 \times 10^{-6}$ & $\mathrm{~kg}$ \\
\hline Damping ratio $b_{1}$ & $1 \times 10^{-6}$ & $\mathrm{~N}-\mathrm{s} / \mathrm{m}$ \\
\hline Viscous friction $b_{2}$ & $10 \times 10^{-6}$ & $\mathrm{~N}-\mathrm{s} / \mathrm{m}$ \\
\hline Stiffness $k$ & $57 \times 10^{3}$ & $\mathrm{~N} / \mathrm{m}$ \\
\hline
\end{tabular}

Fig. 6 presents the electromechanical relations for the ULM sample considered. Fig. 6a shows the frequency response of Eq. (3). Note that the resonance frequency of the actuator is $75 \mathrm{kHz}$ with a gain margin of $-70,3 \mathrm{~dB}$. This means that the slider performs a 93,3 nm displacement per cycle. Eq. (4) permits to estimate its speed at $7 \mathrm{~mm} / \mathrm{s}$.

$$
\begin{aligned}
\text { Speed } & =\text { displacement_per_cycle } \times \text { frequency }= \\
& =\left(93,3 \times 10^{-6} \mathrm{~mm}\right)\left(75 \times 10^{3} \mathrm{~s}^{-1}\right)=7 \mathrm{~mm} / \mathrm{s}
\end{aligned}
$$

Fig. $6 \mathrm{~b}$ shows the evolution of voltage $U_{\mathrm{p}}$ when a square wave input voltage $U$ of $15 \mathrm{~V}$ at $75 \mathrm{kHz}$ with $70 \%$ of duty cycle is applied (Eq. (1)). Note that the electrical behaviour of the piezoelectric motor is effectively that of a high-frequency capacitor.

Fig. 6c shows the relation between voltage $U_{\mathrm{p}}$ and transduced force $F_{\mathrm{p}}$, Eq. (2). Note that the transducer delivers $120 \mathrm{mN}$ forces to the shaft.

Fig. $6 \mathrm{~d}$ shows the temporal evolution of the slider displacement $y_{2}$, Eq. (3). Note that, contrary to the operation principle shown in Fig. 3a, the slider actually slips backwards when moving along the shaft. However, this backwards distance is negligible compared to the forward displacement (Fig. 6d inset).

\section{Experimental evaluation}

Experimental procedures should also be conducted to determine the conditions that allow operating optimally ULMs at their resonance frequency. This section addresses driving signal, force, and electrical considerations that have a significant impact on ULMs' performance. 


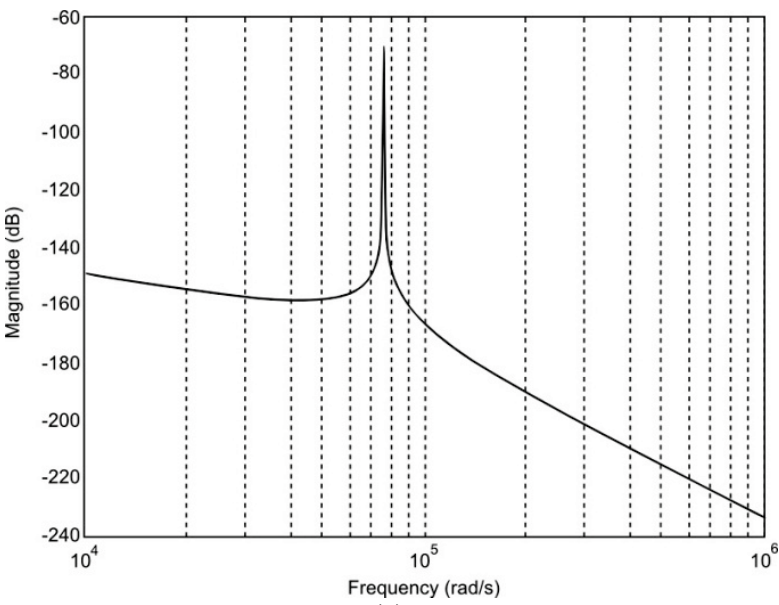

(a)

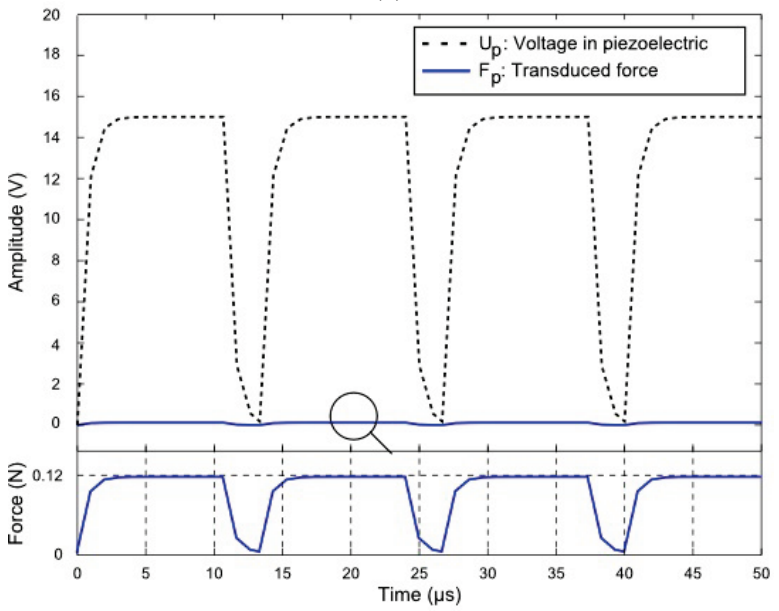

(c)

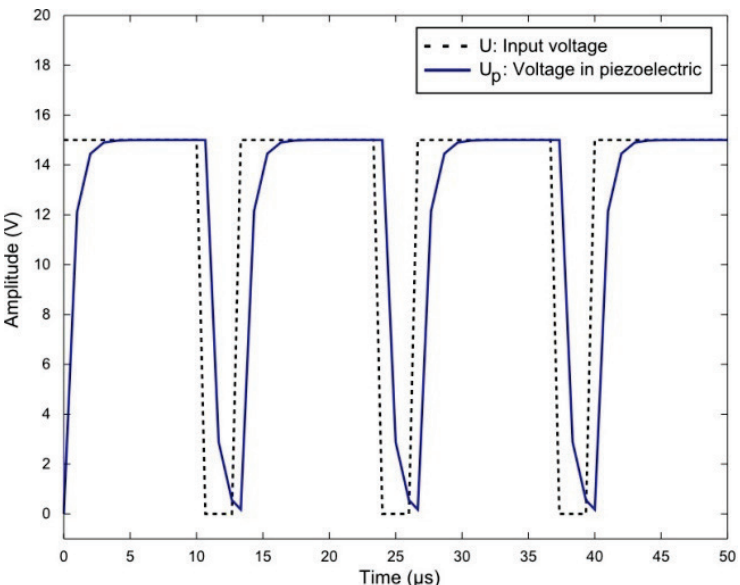

(b)

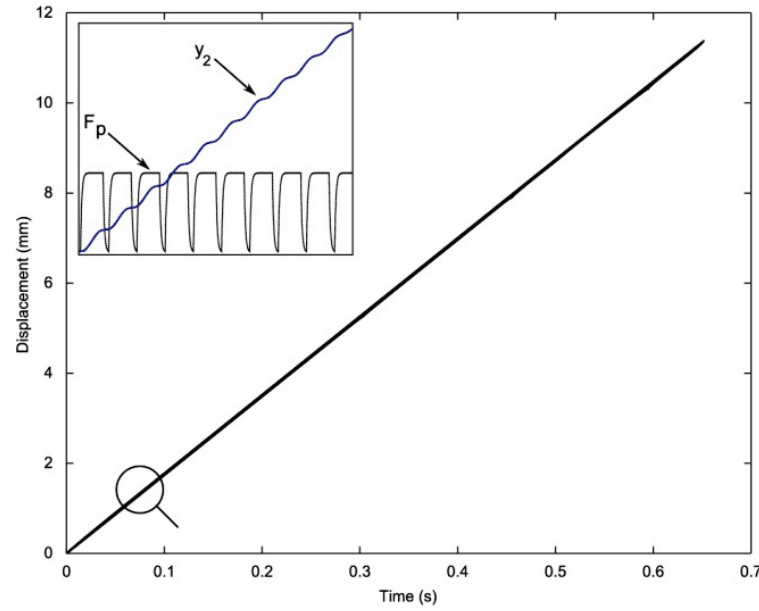

(d)

Figure 6 a) Bode plot, b) electrical, c) piezoelectric, and d) mechanical numerical simulations for the ULM sample considered

\subsection{Driving signal}

One of the key parameters for ULMs is undoubtedly the driving signal. It is of much interest to determine the relation between the characteristics of the input command signal (voltage, frequency, and duty cycle) and the output speed of the ULM [25].

As illustrative example, let us still consider the ULMdevice from Fig. 1b. The first step is to determine the best duty cycle for the ULM. Recall that the duty cycle is the variable responsible for the vibration amplitude of the transducer and therefore for the slider's motion.

For this test, a $15 \mathrm{~V}$ square wave voltage signal at 75 $\mathrm{kHz}$ was used. Duty cycle was gradually increased from 10 to $90 \%$ in steps of $2 \%$. For each duty cycle, the slider's speed was measured.

Fig. 7 shows the results obtained. Note a symmetric behaviour that indicates that the ULM's speed is the same for duty cycles of $x \%$ and $(100-x) \%$. The only difference between both is the direction of motion. Also note that the highest speed is obtained at duty cycles of $30 \%$ and $70 \%$ and that the ULM has no response for duty cycles below $12 \%$, above $88 \%$, and between $46 \div$ $54 \%$.

Once the duty cycle-speed behaviour is known, the second step is to characterize the relation between the input's voltage and frequency and the slider's speed.
A square wave voltage signal with $70 \%$ of duty cycle was chosen. Voltage was gradually increased from 8 to $24 \mathrm{~V}$ in steps of $2 \mathrm{~V}$. Frequency was gradually increased as well from 38 to $110 \mathrm{kHz}$ in steps of $2 \mathrm{kHz}$. This combination produces 333 speed samples that are large enough to characterize the ULM behaviour.

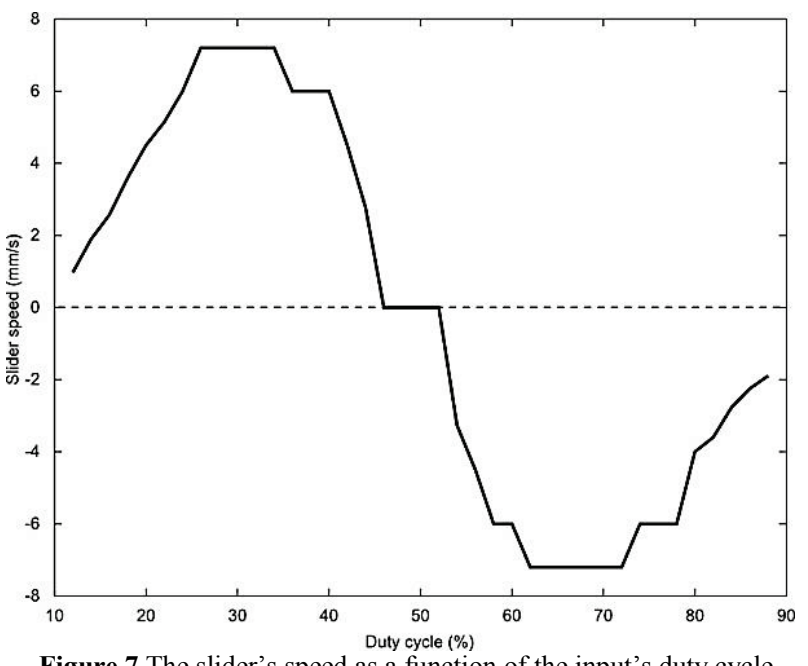

Figure 7 The slider's speed as a function of the input's duty cycle

Fig. 8a shows the ULM's experimental behaviour in the speed-frequency-voltage space. To understand this surface, let us consider first the relation between speed and frequency. 


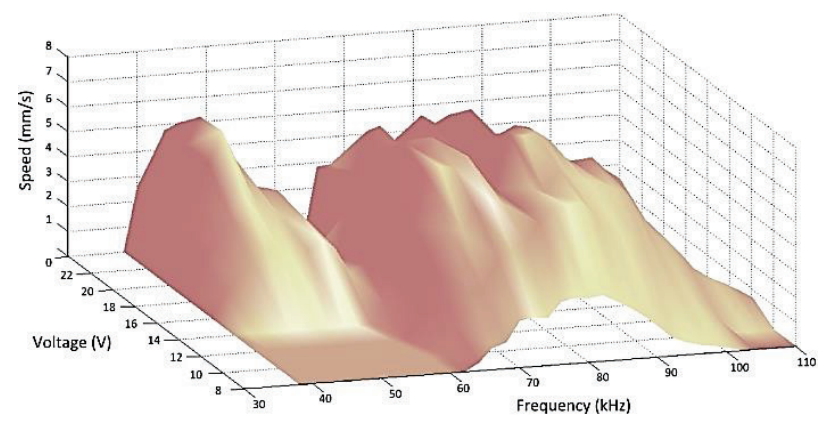

a)

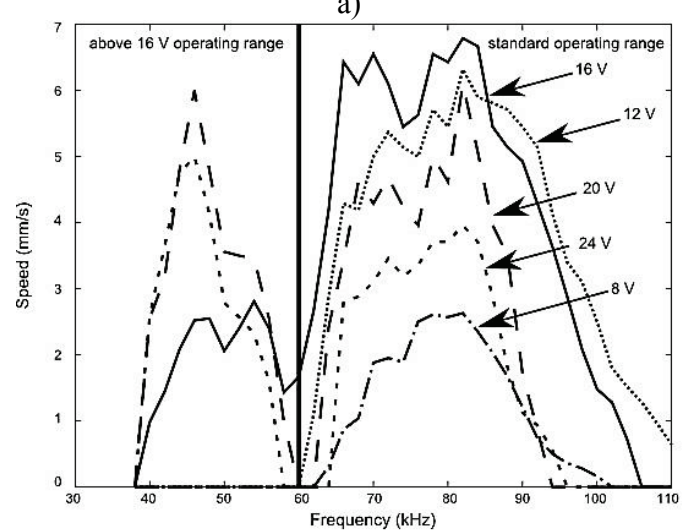

b)

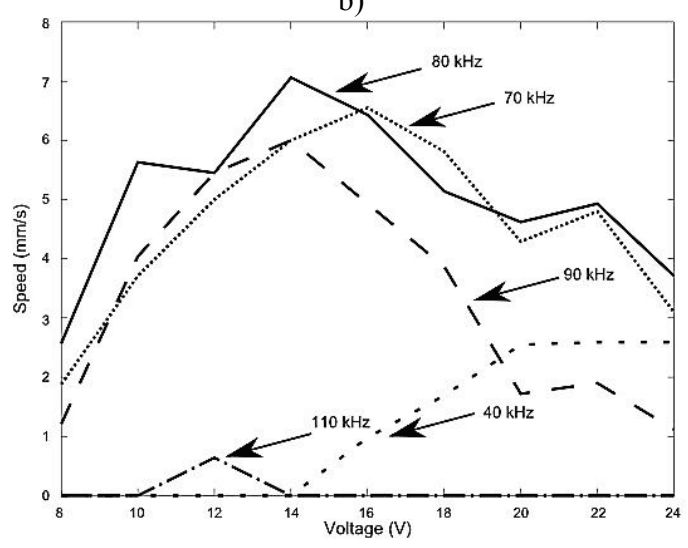

c)

Figure 8 Experimental relations for the ULM sample: a) behaviour in the speed-frequency-voltage space, b) speed-frequency, and c) speedvoltage curves.

Fig. $8 \mathrm{~b}$ shows this relation for a set of input voltages. Note that there is a dead zone between $56 \div 62 \mathrm{kHz}$. The curve reveals that the maximum speed is developed at 16 $\mathrm{V}$. Note, for example, that approximately the same speed is developed at $12 \mathrm{~V}$ and $20 \mathrm{~V}$. Then, it is no worth to supply more than $16 \mathrm{~V}$ to the ULM. Finally, the curve reveals two operating zones: $44 \div 56 \mathrm{kHz}$ and $62 \div 110$ $\mathrm{kHz}$. Note that minimum $16 \mathrm{~V}$ are needed to drive the ULM in the $44 \div 56 \mathrm{kHz}$ range. Lower voltages do not produce any response within this range.

Let us consider now the relation between speed and voltage. Fig. 8c shows this relation for a set of input frequencies. Note a good performance between the $70 \div$ $90 \mathrm{kHz}$ range, which was correctly predicted by the frequency response plot of Fig. 6a. Again, for frequencies below $60 \mathrm{kHz}$, there is only response for voltages above $16 \mathrm{~V}$. Finally, note that above $16 \mathrm{~V}$, the ULM's performance worsens considerably.

From this experimental analysis, it can be established that the best performance is obtained when supplying the ULM sample input square wave signals within $14 \div 16 \mathrm{~V}, 70 \div 80 \mathrm{kHz}$, and 30 or $70 \%$ duty cycle depending on the desired direction of motion.

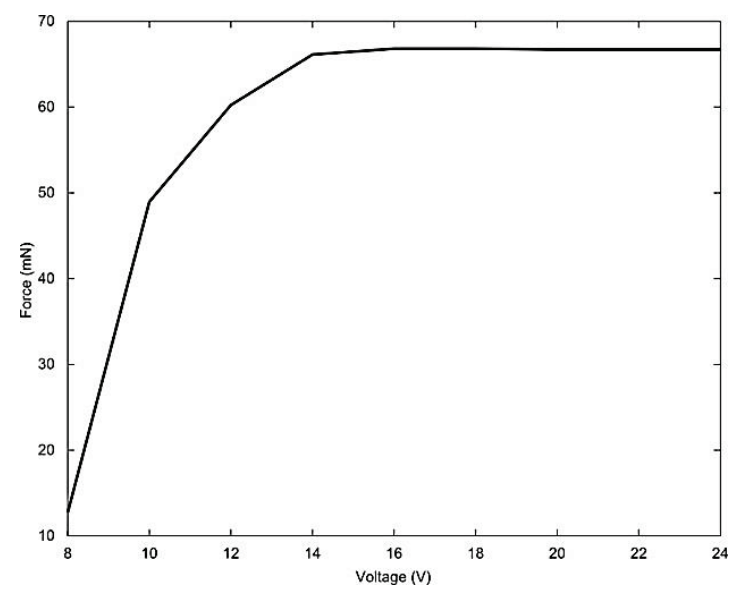

a)

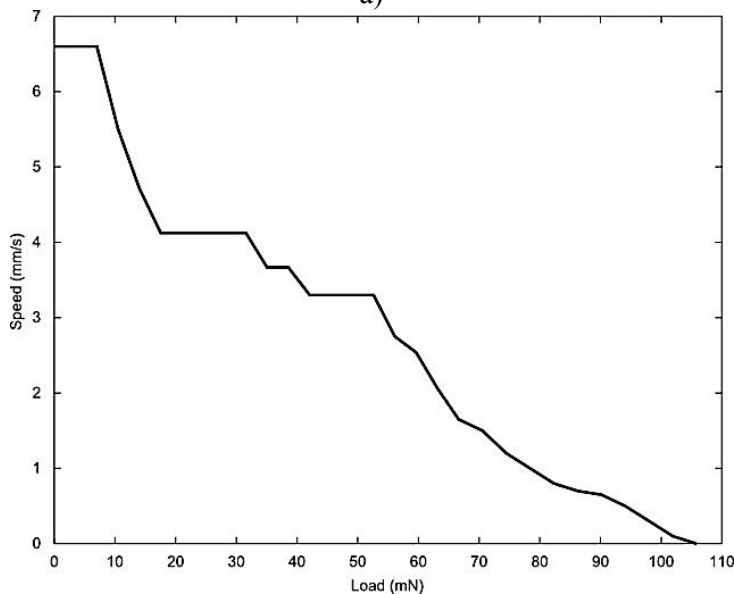

b)

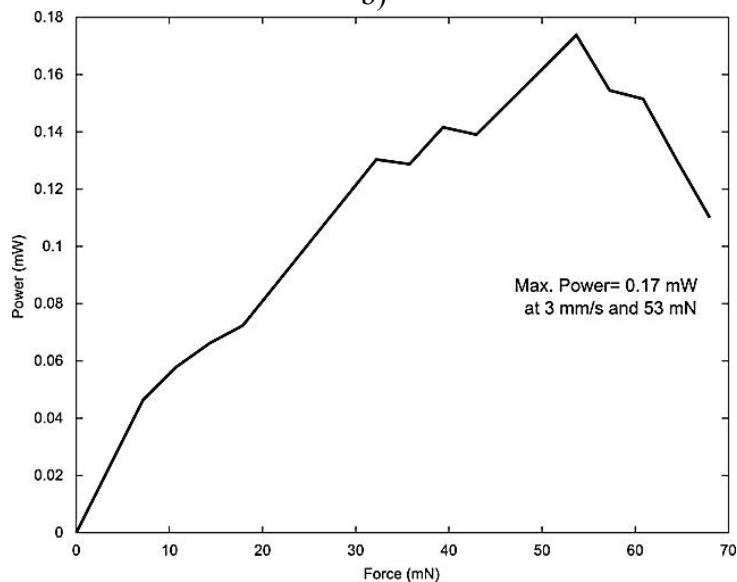

c)

Figure 9 Experimental force relations for the ULM sample considered: a) voltage-force, b) speed-load, and c) power-force curves.

\subsection{Force considerations}

Experimental procedures can also be conducted to determine the force developed by ULMs. In particular, the relations between force and input voltage, force and speed, and force and mechanical power give users useful information on the performance to be expected when positioning a mechanism.

For the force tests, a load was physically attached to the slider. It was gradually increased from 6 to $120 \mathrm{mN}$ 
in steps of $6 \mathrm{mN}$. Tests were conducted at optimal conditions of square wave input signal: $15 \mathrm{~V}, 75 \mathrm{kHz}, 70$ $\%$ duty cycle.

For the ULM sample considered, plots in Fig. 9 describe the force experimental relations. Fig. 9a shows the relation between force and input voltage. Note that a maximum force of $68 \mathrm{mN}$ is achieved at $14 \mathrm{~V}$. Beyond this voltage, the nominal force delivered by the ULM is practically the same.

Fig. $9 \mathrm{~b}$ shows the relation between load (or resistive force) and speed. As any other actuator, speed decreases with load. Note that the $7 \mathrm{~mm} / \mathrm{s}$ speed estimated in Eq. (4) is the no-load speed while approximately $108 \mathrm{mN}$ are required to stop the slider's motion completely.

The force-speed relation in Fig. $9 \mathrm{~b}$ is useful to obtain an approximate of the mechanical power delivered by the ULM. Recall that the mechanical power in linear motion can be defined as Eq. (5):

$$
\text { Power }=\text { Speed } \times \text { Force } \text {. }
$$

Fig. 9c shows the relation between force and mechanical power for the ULM considered. Note that the actuator delivers a maximum power of $0,17 \mathrm{~mW}$ at 53 $\mathrm{mN}$ and $3 \mathrm{~mm} / \mathrm{s}$.

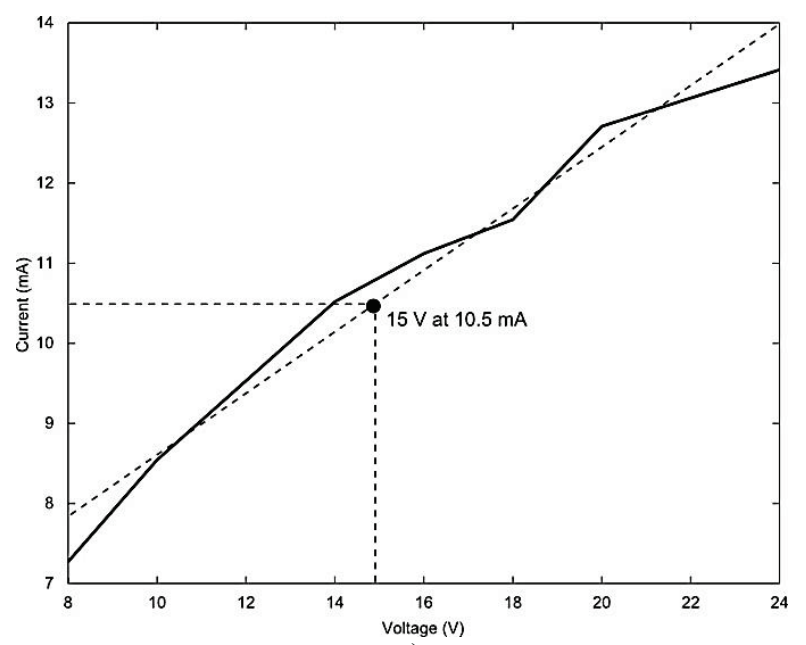

a)

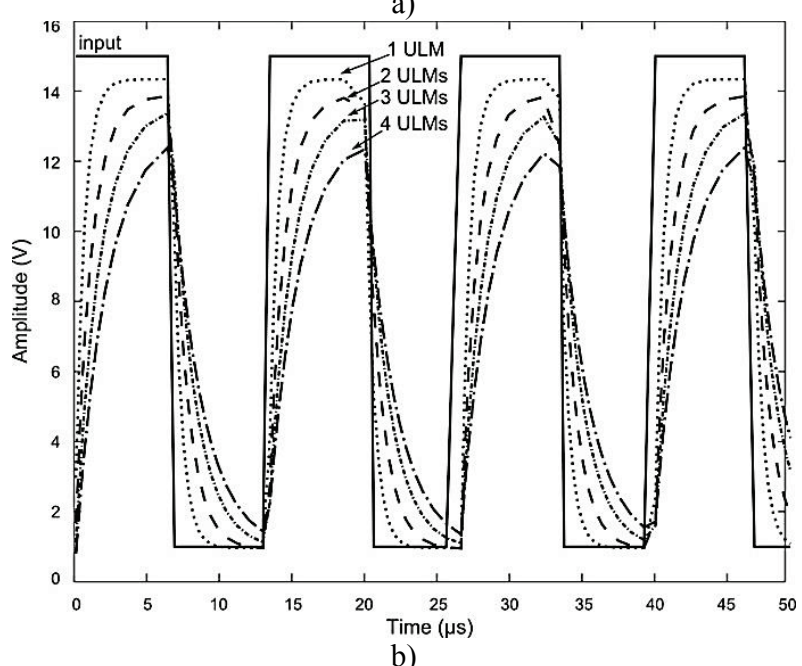

Figure 10 Electrical considerations for the ULM sample considered: a) voltage-current curve and $b$ ) reduction of the effective voltage according to the number of ULMs actuated

\subsection{Electrical considerations}

Two important electrical considerations of ULMs are power consumption and electrical behaviour when driven in a group of two or more ULMs.

Fig. 10a shows the experimental voltage-current relation for the ULM sample considered. Note a fairly linear behaviour. The $15 \mathrm{~V}$ ideal operating point requires $10,5 \mathrm{~mA}$ from the power source. Note that supplying high voltages $(>16 \mathrm{~V})$ to the ULM not only produces the worst performances (Fig. 8c) but also requires the higher currents.

Another key feature, especially for the electronic drive, is that piezoelectric materials behave electrically as capacitors (recall Fig. 6b). When too many ULMs are connected in parallel to the same driver-output, the total capacitance increases considerably, making the supplied signal to be so distorted that it can no longer comply with the $15 \mathrm{~V}, 75 \mathrm{kHz}$ requirement, causing an unreliable performance of the motors (low speed or even no movement) [25]. Fig. 10b illustrates the degradation of the wave as more ULMs are supplied by the same output-signal. This effect forces to have each ULM supplied by its own driver.

\section{Conclusion}

This paper has presented an analytical-experimental study of ultrasonic linear actuators (ULMs) and intends to serve as a research-practical guide for their evaluation and use.

The general structure and operation principle of an ULM were discussed. Its mechanics was formulated based on a simple electromechanical model for piezoelectric actuators. What this paper added is the mechanical relation between shaft and slider which allows the construction of an overall model for ULMs. The resonance frequency associated with the mechanical behaviour, the displacement per cycle, and the speed of a ULM can be easily predicted using this model. Furthermore, the proposed model is useful for precise positioning applications and model-based controller design.

The actuation properties of ULMs have been experimentally investigated. In practice, a set of usage conditions determine their performance. In fact, ULMs' performance greatly varies depending on driving signal, force, and electrical conditions. To determine the optimal driving signal for a specific ULM, a good initial guess is the resonance frequency estimated by modelling. Then, the signal's appropriate duty cycle, voltage, and frequency can be determined to achieve the maximum speed. Then, it is convenient to evaluate their force performance as ULMs are usually required to move other mechanisms. The force-input voltage, load-speed, and force-mechanical power relations give users information on the performance to be expected when positioning a mechanism. Finally, electrical conditions give useful information when choosing a battery or when designing an electronic drive to control a set of ULMs. 


\section{References}

[1] Gandhi, M.V.; Thompson,B.S. Smart Materials and Structures. Chapman \& Hall, London, 2000.

[2] Barth, H. V. Ultrasonic driven motor. // IBM Technical Disclosure Bulletin. 16, 7(1973), pp. 2263-2265.

[3] Gromakovskii, V. On the possibility of using a piezoelectric motor for direct actuation of the shaft of a video tape recorder. // Tekhnika kino i televideniya. 5 (1978), pp. 33-43.

[4] Vasiliev, P. E. UK Patent Application GB 2020857-A, 1979.

[5] Sashida, T.; Kenjo, T. An introduction to ultrasonic motors. Oxford University Press, Oxford, 1993.

[6] Uchino, K. Piezoelectric ultrasonic motors: overview. // Smart Materials and Structures. 7 (1998), pp. 273-285. DOI: 10.1088/0964-1726/7/3/002

[7] Velázquez, R.; Hernández, H.; Preza, E. A portable piezoelectric tactile terminal for Braille readers. // Applied Bionics and Biomechanics. 9, 1(2012), pp. 45-60. DOI: 10.1155/2012/637851

[8] Suzuki, T.; Liao, H.; Kobayashi, E.; Sakuma, I. Ultrasonic motor driving method for EMI-free image in MR imageguided surgical robotic system. // Proceedings of IEEE/RSJ International Conference on Intelligent Robots and Systems, San Diego, 2007, pp. 522-527. DOI: 10.1109/iros.2007.4399391

[9] Higuchi, T. Innovative actuators and tools for micro-nano mechatronics. // Proceedings of IEEE International Symposium on Micro-NanoMechatronics and Human Science, Nagoya, 2005, pp. 5-9. DOI: 10.1109/mhs.2005.1589955

[10] Bansevicius, R.; Blechertas, V. Ultrasonic motors for mass-consumer products. // Ultragarsas. 4, 61(2006), pp. 50-52.

[11] Iino, A.; Suzuki, K.; Kasuga, M.; Suzuki, M.; Yamanaka, T. Development of a self-oscillating ultrasonic micromotor and its application to a watch. // Ultrasonics. 38 (2000), pp. 54-59. DOI: 10.1016/S0041-624X(99)00192-4

[12] Toyama, S.; Kobayashi, A. Development of spherical ultrasonic motor. // CIRP Annals of Manufacturing Technology. 45,1(1996), pp. 27-30. DOI: 10.1016/S00078506(07)63010-8

[13] Park, H.; Kim, B.; Park, J.; Yoon, S. A crawling based locomotive mechanism using a tiny ultrasonic linear actuator (TULA). // Proceedings of 39th International Symposium on Robotics/ Seoul, 2008, pp. 85-90.

[14] Yamano, T.; Maeno, T. Five-fingered robot hand using ultrasonic motors and elastic elements. // Proceedings of IEEE International Conference on Robotics and Automation/ Barcelona, 2005, pp. 2684-2689. DOI: 10.1109/robot.2005.1570517

[15] PiezoTech Co. Tiny piezo-actuator TULA.URL: $\mathrm{http} / / / \mathrm{www}$. piezo-tech.com/eng/ (18.11.2014)

[16] Ko, H.; Kim, S.; Borodinas, S.; Vasiljev, P.; Kang, C.; Yoon, S. A novel tiny ultrasonic linear motor using the radial mode of a bimorph. // Sensors and Actuators A. 125, (2006), pp. 477-481. DOI:10.1016/j.sna.2005.07.014

[17] IEEE Standard on Piezoelectricity. ANSI/IEEE Standard No. 176,1987

[18] Adriaens, H.; de Koning, W.; Banning, R. Modeling piezoelectric actuators. // IEEE/ASME Transactions on Mechatronics. 5, 4(2000), pp. 331-341. DOI: 10.1109/3516.891044

[19] Clinton, C.; Liyong, T.; Grant, S. A review on the modelling of piezoelectric sensors and actuators incorporated in intelligent structures. // Journal of Intelligent Material Systems and Structures. 9, 1(1998), pp. 3-19. DOI: 10.1177/1045389X9800900101
[20] Dimmler, M.; Holmberg, U.; Longchamp, R. L. Hysteresis compensation of piezo-actuators. // Proceedings of $5^{\text {th }}$ European Control Conference, Karlsruhe, 1999, CDROM paper f0700.

[21] Newcomb, C. V.; Flinn, I. Improving the linearity of piezoelectric ceramic actuators. // Electronic Letters. 18 (1982), pp. 442-444. DOI: 10.1049/el:19820301

[22] Pozzi, M.; King, T. Dynamic characteristics of piezoelectric multilayer stack actuators. // Proceedings of $2^{\text {nd }}$ International Conference on Recent Advances on Mechatronics/ Istanbul, 1999, pp. 461-466.

[23] Yang, S.; Huang, W. Dynamic analysis of piezoelectric elements. // Review of Scientific Instruments. 66 (1995), pp. 4157-4160. DOI: 10.1063/1.1145363

[24] Goldfarb, M.; Celanovic, N. Modeling piezoelectric stack actuators for control of micromanipulation. // IEEE Control Systems Magazine. 17 (1997), pp. 69-79. DOl: 10.1109/37.588158

[25] Velázquez, R.; Hernández, H.; Preza, E. A portable eBook reader for the blind. // Proceedings of 32nd Annual International Conference of the IEEE Engineering in Medicine and Biology Society/ Buenos Aires, 2010, pp. 2107-2110. DOI: 10.1109/iembs.2010.5626218

\section{Authors' addresses}

Ramiro Velázquez, PhD, AssociateProfessor

Universidad Panamericana

Fracc. Rústicos Calpulli, 20290,

Aguascalientes, Mexico

E-mail: rvelazquez@up.edu.mx

Hermes Hernández, MSc, Research Assistant Universidad Panamericana

Fracc. Rústicos Calpulli, 20290,

Aguascalientes, Mexico

E-mail: posgradosingenieria_ags@up.edu.mx

Carlos A. Gutiérrez, PhD, Associate Professor Universidad Autónoma de San Luis Potosí

Av. Salvador Nava Mtz S/N, 78290

San Luis Potosí, Mexico

E-mail: cagutierrez@fc.uaslp.mx

\section{Pedro Rodrigo, PhD}

Universidad de Jaén

Campus Las Lagunillas S/N, 23071,

Jaen, Spain

E-mail: prodrigo@ujaen.es 